\title{
Processamento sintático e fonológico de crianças com dificuldades de aprendizagem
}

\author{
Syntactic and phonological processing \\ of children with learning disabilities
}

\author{
Procesamiento sintáctico y fonológico \\ de niños con dificultades de aprendizaje
}

\author{
Isabella Passos Guarald* \\ Tatiana Bagetti*
}

\section{Resumo}

Introdução: As dificuldades de aprendizagem são muito conhecidas pelo baixo desempenho escolar, porém, é importante diferenciá-las e entender suas origens e sintomas. Objetivo: Este estudo teve como objetivos verificar habilidades de processamentos fonológico e sintático em escolares com dificuldades de aprendizagem e investigar se alterações são sobrepostas, podendo indicar possível alteração de linguagem. Métodos: Participaram deste estudo 30 escolares, na faixa etária de sete a 11 anos, de ambos os gêneros, do $2^{\circ}$ ao $5^{\circ}$ ano do Ensino Fundamental, divididos em grupo experimental e controle. Foram avaliadas a nomeação rápida de figuras, repetição de pseudopalavras, leitura de palavras e pseudopalavras, consciência fonológica e compreensão do processamento sintático. Os resultados foram analisados por meio de testes estatísticos, Resultados: Observou-se diferença estatisticamente significativa entre os desempenhos dos participantes com e sem dificuldades de aprendizagem para a maioria das habilidades de processamento fonológico, indicando melhores resultados do grupo controle. Além disso, houve diferença de desempenho em função da idade para o grupo experimental nas tarefas de processamento fonológico, com melhores rendimentos de crianças mais velhas. A respeito do processamento sintático, não foram verificadas diferenças estatísticas significativas entre os grupos, sendo observada uma sutil diferença entre as idades apenas em relação à compreensão das relativas encaixadas de objeto com verbo transitivo. Conclusão: O desempenho das crianças com dificuldades de aprendizagem demonstra-se alterado somente para as habilidades de processamento fonológico. Quanto ao processamento sintático,

* Universidade Federal Fluminense, Rio de Janeiro, RJ, Brasil.

Contribuição dos autores

IPG: Participou da concepção e delineamento do estudo. Realizou a coleta e análise de dados e escrita do artigo.

TB: Foi responsável pela concepção e delineamento do estudo, pela orientação, análise dos dados. Participou da escrita e revisão do artigo.

E-mail para correspondência: Tatiana Bagetti - tatianabagetti@id.uff.br Recebido: 23/02/2021

Aprovado: 09/08/2021 
os grupos apresentaram resultados semelhantes; no entanto é necessário aumentar o tamanho da amostra para resultados conclusivos.

Palavras-chave: Linguagem Infantil; Desenvolvimento da Linguagem; Transtornos do Desenvolvimento da Linguagem; Aprendizagem; Deficiências da Aprendizagem.

\section{Abstract}

Introduction: Learning difficulties are well known for poor school performance, however, it is important to differentiate them and understand their origins and symptoms. Objective: This study aimed to verify phonological and syntactic processing skills in students with learning difficulties and to investigate whether changes are overlapping, which may indicate possible changes in the underlying language. Methods: This study involved 30 schoolchildren, ages seven to 11, of both genders, from 2nd to 5th grade, divided into experimental and control group. Tools were used to evaluate the rapid naming of figures, repetition of pseudowords, reading of words and pseudowords, phonological awareness and understanding of syntactic processing. The results were analyzed through statistical tests. Results: A statistically significant difference was observed between the performances of participants with and without learning difficulties for most phonological processing skills, indicating better control group results. In addition, there was an age-related performance difference for the experimental group in phonological processing tasks, with better yields for older children. Regarding syntactic processing, no significant statistical differences were found between the groups, and a subtle difference between ages was observed only in relation to the understanding of the relative fit of object with transitive verb. Conclusion: The performance of children with learning difficulties is shown to have changed only for phonological processing skills. Regarding syntactic processing, the groups showed similar results; however it is necessary to increase the sample size for conclusive results.

Keywords: Child Language; Language Development; Language Development Disorders; Learning; Learning Disabilities.

\section{Resumen}

Introducción: Las dificultades de aprendizaje son bien conocidas por el bajo rendimiento escolar, sin embargo, es importante diferenciarlas y comprender sus orígenes y síntomas. Objetivo: Este estudio tuvo como objetivo verificar habilidades de procesamientos fonológico y sintáctico en estudiantes con dificultades de aprendizaje y investigar si cambios se superponen, que puede indicar un posible cambio en el lenguaje subyacente. Metodos: Participaron de este estudio treinta estudiantes, de 7 a 11 años, de ambos sexos, de $2^{\circ}$ a $5^{\circ}$ de la primaria, divididos em grupo experimental y control. Se evaluó la denominación rápida de figuras, repetición de pseudopalabras, lectura de palabras y pseudopalabras, conciencia fonológica y comprensión del procesamiento sintáctico. Los resultados fueron analizados mediante pruebas estadísticas. Resultados: Se observó una diferencia estadísticamente significativa entre desempeños de participantes con y sin dificultades de aprendizaje para mayoría de las habilidades de procesamiento fonológico, indicando mejores resultados del grupo control. Además, hubo una diferencia en el desempeño en función de la edad para el grupo experimental en tareas de procesamiento fonológico, con mejores rendimientos de niños mayores. En relación al proceso sintáctico no se observan diferencias estadísticas considerables entre los grupos, observándose una pequeña diferencia entre edades solamente relacionada a la comprensión de relativas adecuadas de complemento con verbo transitivo. Conclusión: El desempeño de niños con dificultades de aprendizaje se muestra alterado solamente para habilidades de procesamiento fonológico. En cuanto al procesamiento sintáctico, los grupos mostraron resultados similares, sin embargo, es necesario aumentar el tamaño de la muestra para obtener resultados concluyentes.

Palabras clave: Lenguaje Infantil, Desarrollo del Lenguaje; Trastornos del Desarrollo del Lenguaje; Aprendizaje; Discapacidades para el Aprendizaje. 


\section{Introdução}

As dificuldades de aprendizagem são muito conhecidas pelo baixo desempenho escolar que acarretam em crianças na maioria dos casos, porém, é importante diferenciá-las e entender suas origens e manifestações. Essas referem-se a um grupo de diferentes alterações que podem manifestar-se de diversas formas nas áreas da leitura, escrita e matemática em crianças sem déficits sensoriais, motores, cognitivos e intelectuais ${ }^{1}$.

Quanto a sua etiologia, diferentes concepções são apresentadas em produções acadêmicas ${ }^{2}$. Dessa forma, são divididos os trabalhos que defendem a origem em fatores intrínsecos, das obras que acreditam nos fatores extrínsecos como etiologia das dificuldades de aprendizagem. Os primeiros são relacionados a questões neurológicas e muitas vezes estão associados ao termo 'Transtornos de Aprendizagem', enquanto o segundo engloba fatores psicopedagógicos e/ou socioculturais ${ }^{2}$.

Alguns estudos estabelecem a relação entre dificuldades de aprendizagem com alterações fonológicas, tendo em vista a influência do processamento fonológico no desenvolvimento da leitura e escrita ${ }^{3}$. Portanto, é necessário entender quais habilidades fazem parte desse processo e como cada uma pode impactar na aprendizagem da criança.

O processamento fonológico foi definido como "uso da informação fonológica no processamento da linguagem oral e escrita" ${ }^{4}$ e, segundo os autores ${ }^{4}$, engloba três habilidades principais, sendo estas: consciência fonológica, resgate lexical e memória de trabalho.

A consciência fonológica é conceituada como a habilidade de compreender e manipular os sons que constituem as palavras, chamados de fonemas, os quais podem ser combinados de diferentes formas a fim de gerar novas sílabas e palavras ${ }^{5}$. Os autores mencionam a importância dessas habilidades para o desenvolvimento da leitura e escrita.

O resgate lexical, também conhecido como acesso ao léxico, relaciona-se com a fluência da leitura ${ }^{3,6}$. Pesquisas apontam que crianças com dificuldades de aprendizagem apresentam dificuldades em tarefas de nomeação rápida e fluência, tendo em vista a necessidade de acesso rápido ao léxico envolvida nestas tarefas. ${ }^{7,8}$.

A memória de trabalho fonológica, também conhecida como memória de curto prazo fonológica, é outra habilidade do processamento fonológico e envolve o armazenamento temporário da informação ${ }^{9}$. Além disso, participa de diversas funções cognitivas e, portanto, alterações nessa habilidade podem gerar prejuízos para a linguagem, aprendizagem e raciocínio matemático ${ }^{10}$.

Alguns estudos apontam que além do processamento fonológico, alterações no processamento sintático geram impacto não apenas no desenvolvimento linguístico, mas também na aprendizagem ${ }^{7,8}$. No entanto, determinadas pesquisas desenvolvidas há um tempo preconizam que é o processamento fonológico que está comprometido, mais especificamente a consciência fonológica, pois demonstram uma correlação positiva dessa alteração na consciência fonológica e alterações de aprendizagem ${ }^{11,12}$.

O processamento sintático está envolvido na compreensão e na produção de frases simples e complexas, ou seja, de diferentes custos computacionais. As sentenças de maior custo computacional são aquelas que envolvem um movimento sintático, ou seja, algum elemento da frase foi deslocado de seu lugar original e, portanto, a frase demandará maior processamento para sua compreensão ou produção. Entre essas, destacam-se as que possuem voz passiva, interrogativas iniciadas por que/quem e sentenças relativas de sujeito, objeto e relativas encaixadas. Além disso, os deslocamentos de objeto na sentença demandam maior custo computacional do que o deslocamento de sujeito, sendo as sentenças relativas de objeto as de maior custo computacional ou maior demanda de processamento sintático ${ }^{13}$.

Parte das pesquisas que abordam o processamento sintático em alterações de linguagem e aprendizagem defende a hipótese de que comprometimentos no processamento fonológico dificultariam, por exemplo, a retenção das sentenças para posterior análise e compreensão ${ }^{7,14}$. Por outro lado, alguns estudos demonstram que essas alterações não são apenas consequências de limitações fonológicas, mesmo que os processamentos sintático e fonológico compartilhem habilidades, como memória de trabalho auditiva e habilidades metalinguísticas ${ }^{8}$.

A respeito dos déficits sintáticos nas alterações de linguagem, o Distúrbio Específico de Linguagem (DEL) destaca-se em relação à compreensão de orações de alto custo computacional. Há indícios em diversas línguas, de que crianças com DEL apresentam dificuldades com essas sentenças ${ }^{13}$. 
Atualmente, o termo DEL está em desuso, sendo comumente chamado de Transtorno do Desenvolvimento da Linguagem (TDL). Portanto, usaremos esta terminologia no decorrer do artigo.

Segundo Leonard, em 1998, o Transtorno do Desenvolvimento da Linguagem envolve alterações exclusivamente linguísticas de diferentes naturezas, como dificuldades sintáticas, fonológicas, morfológicas, pragmáticas e lexicais e tem como possíveis causas fatores neurobiológicos ${ }^{15}$. Contudo, "o DEL sintático é uma manifestação característica do DEL. Crianças com TDL em idade escolar frequentemente apresentam alterações de aprendizagem ${ }^{13}$.

Diante disso, considerando que crianças com Transtorno do Desenvolvimento da Linguagem têm como principal manifestação o comprometimento sintático, e que muitas crianças com transtornos de aprendizagem apresentam alterações no processamento fonológico, surge a importância do presente estudo. Sendo assim, este estudo tem como objetivos verificar o desempenho de habilidades de processamentos fonológico e sintático em crianças com queixas de dificuldades de aprendizagem. Também pretende-se investigar se alterações no processamento fonológico também são acompanhadas ou sobrepostas a alterações no processamento sintático. Dessa forma, pode-se pressupor uma diferenciação entre aqueles participantes que apresentam transtornos do desenvolvimento da linguagem (TDL) e também alterações de aprendizagem, daqueles que apresentam somente dificuldades ou transtornos de aprendizagem.

Dados como esse podem servir para um maior conhecimento das manifestações dessas alterações, contribuindo, assim, para o diagnóstico e tratamento de futuras intervenções fonoaudiológicas. Para isso, também é necessário obter dados sobre o desempenho de participantes com desenvolvimento normal de aprendizagem, e, após, compará-los com os de participantes que apresentam alterações nesse processo.

\section{Método}

O presente estudo foi aprovado pelo Comitê de Ética em Pesquisa do Instituto de Saúde de Nova Friburgo da Universidade Federal Fluminense sob o parecer de número 2.555.867 e pela Secretaria de Educação do Município de Nova Friburgo sob o processo administrativo de número 24.527/2017.
A fim de alcançar os objetivos propostos foi realizada uma pesquisa exploratória do tipo transversal. Os participantes foram divididos em dois grupos: grupo experimental (GE): composto por crianças com queixas de dificuldades de aprendizagem e grupo controle (GC): constituído por crianças com desenvolvimento normal de linguagem e aprendizagem.

Os procedimentos foram realizados após apresentação e aprovação dos termos de concordância das instituições envolvidas. A seleção de GE foi feita na Clínica Escola de Fonoaudiologia da Universidade Federal Fluminense a partir da análise dos prontuários, mediante contato com a coordenação da clínica e com os orientadores/ supervisores responsáveis pelo estágio, que autorizaram a realização da pesquisa. Para a composição do GC, realizou-se uma reunião com a direção e com os professores da Escola Municipal Jardel Hottz, no Município de Nova Friburgo, a fim de selecionar alunos que se enquadrassem nos critérios de inclusão e exclusão e tivessem desempenho escolar acima de 6.0, considerado como um bom rendimento. Esse parâmetro foi obtido a partir das médias específicas do primeiro bimestre de 2018 das disciplinas de Língua Portuguesa, Matemática, Ciências, História e Geografia, que resultaram em uma média geral envolvendo as mesmas, que se caracterizou como a média do aluno. Foram analisadas apenas as notas do primeiro bimestre tendo em vista o início da pesquisa no segundo bimestre do mesmo ano.

Posteriormente, os responsáveis legais dos participantes selecionados, do GE, foram contatados para explicação da pesquisa e apresentação do Termo de Consentimento Livre e Esclarecido (TCLE). Na escola, os termos foram enviados aos responsáveis, que retornaram os termos assinados. A partir da assinatura do TCLE, foi apresentado o Termo de Assentimento Livre e Esclarecido para as crianças que tiveram autorização dos responsáveis. Os pais ou responsáveis e as crianças foram informados que a sua participação era voluntária e caso desejassem, poderiam desistir de participar da pesquisa, a qualquer momento, sem prejuízos para nenhuma das partes.

Ao término do estudo, todos os participantes receberam uma devolutiva sobre seus desempenhos gerais na pesquisa. Além disso, foram fornecidos os resultados quantitativos referentes a cada protocolo aplicado para os integrantes de GE. 
A amostra total foi composta por 30 participantes na faixa etária de sete a 11 anos e 11 meses, de ambos os gêneros. Para melhor análise e comparação dos resultados, os participantes do grupo experimental e do grupo controle foram divididos em dois subgrupos: G1 (grupo 1), o grupo de crianças de sete a nove anos e G2 (grupo 2), o grupo de crianças de 10 e 11 anos.

Integraram o GE, 10 crianças, sendo três do gênero feminino e sete do gênero masculino, que apresentavam queixa de dificuldades de aprendizagem. Essas crianças estavam em atendimento na Clínica Escola de Fonoaudiologia da Universidade Federal Fluminense por no máximo duas sessões de avaliação e/ou terapia voltadas para habilidades de leitura e escrita ou aguardavam atendimento na fila de espera, após terem passado pelo processo de acolhimento da instituição.

Foi considerado como critério de inclusão ter passado pelo acolhimento, pois essa etapa permite a identificação, de uma forma geral, da queixa principal e de outras demandas do paciente, que possibilitam seu direcionamento para os ambulatórios específicos para avaliação mais detalhada $\mathrm{e}$ possível intervenção terapêutica. Nesse processo são realizadas entrevistas com os pais ou responsáveis e uma avaliação básica por meio da aplicação do protocolo PROADE (Proposta de Avaliação das Dificuldades Escolares) adaptado. Por meio desse, são avaliados aspectos relacionados a fala, narrativa, reconhecimento de letras maiúsculas e minúsculas, leitura e escrita, quando a queixa ou a demanda observada durante a entrevista têm relação com os aspectos citados.

Crianças que realizaram mais de duas sessões de terapia voltadas para aprendizagem ou que não passaram pelo processo de acolhimento, assim como aqueles que possuíam queixas ou diagnóstico de alterações auditivas, neurológicas, psiquiátricas ou síndromes foram excluídos da pesquisa.

Foram incluídas crianças que receberam intervenção fonoaudiológica para as habilidades de leitura e escrita por até duas sessões antes da assinatura dos termos e início das avaliações, pois entende-se que nas primeiras sessões geralmente não são observadas evoluções expressivas quanto às dificuldades e alterações apresentadas pelos pacientes, tendo em vista o tempo necessário para estabelecimento de vínculo, avaliações e o início do processo terapêutico envolvidos nessas sessões iniciais.
Em relação ao GC, participaram 20 crianças, na faixa etária de sete a 11 anos, sendo 12 do gênero feminino e oito do gênero masculino, do segundo ao quinto ano do Ensino Fundamental do turno da manhã da Escola Municipal Jardel Hotzz, que possuíam bom desempenho escolar, considerado como sendo acima de 6.0 a média do aluno no primeiro bimestre de 2018 .

Aqueles que possuíam histórico de repetência, queixas ou hipótese diagnóstica de alterações de linguagem, aprendizagem, síndromes, encefalopatia crônica não progressiva, alterações auditivas, neurológicas ou psiquiátricas foram excluídos da seleção do GC.

Nesta pesquisa foram consideradas crianças a partir do segundo ano do Ensino Fundamental que não possuíam diagnóstico, mas possibilidade de apresentar tanto dificuldade como transtorno, pois apresentavam alterações de aprendizagem. Por isso, optou-se por denominar o grupo como possuindo queixas de dificuldades de aprendizagem ou risco para dificuldade ou transtorno de aprendizagem. O mesmo critério de escolaridade foi utilizado também para o grupo controle, ou seja, para crianças sem queixas de dificuldades de aprendizagem.

Com a finalidade de alcançar os objetivos propostos, foram aplicados os seguintes instrumentos de avaliação:

\section{a) Avaliação Fonológica:}

Nomeação Automática Rápida ${ }^{16}$ : foi aplicada a tarefa de nomeação automática rápida de figuras do teste de velocidade de processamento do Protocolo de Avaliação de Habilidades Cognitivo-linguísticas, a fim de avaliar o input visual para acesso de significado. Nessa tarefa, o paciente deveria nomear o mais rápido possível as figuras de um quadro composto por uma série de quatro figuras apresentadas de forma repetida e aleatória. O terapeuta é responsável por marcar o tempo de realização da tarefa.

Brazilian Children's Test of Pseudoword Repetition $^{17}$ adaptado: utilizado para avaliação da memória de trabalho fonológica. Foram apresentadas 40 pseudopalavras para repetição, divididas de acordo com o grau de similaridade com palavras reais, sendo 10 de baixa semelhança, 20 de média e 10 de alta semelhança. Não foram consideradas como erro processos fonológicos identificados previamente por meio de avaliações anteriores ou fala espontânea. Apesar do protocolo dividir as pseu- 
dopalavras pela similaridade com palavras reais, essa classificação não será considerada na análise deste estudo, sendo avaliado apenas o escore total.

Coleção Anele 1 - Avaliação de Leitura de Palavras e Pseudopalavras Isoladas ${ }^{18}$ : objetivou-se avaliar as habilidades envolvidas na leitura de palavras e pseudopalavras. O teste consiste na apresentação de 59 palavras isoladas classificadas em: regulares frequentes curtas (5); regulares frequentes longas (5); regulares não frequentes curtas (4); regulares não frequentes longas (5); irregulares frequentes curtas (5); irregulares frequentes longas (5); irregulares não frequentes curtas (5); irregulares não frequentes longas (5); pseudopalavras curtas (10); pseudopalavras longas (10). Apesar do protocolo dividir os estímulos em curtos e longos, frequentes e não frequentes, neste estudo foi abordado apenas a análise em função da regularidade e da frequência. Dessa forma, todas as pseudopalavras foram agrupadas.

Consciência Fonológica Instrumento de Avaliação Sequencial (CONFIAS) ${ }^{19}$ : a fim de avaliar habilidades dos níveis intra-silábico (rima), silábico e fonêmico da consciência fonológica, por meio das atividades de síntese silábica; segmentação silábica; identificação da sílaba inicial; identificação de rima; produção de palavra com a sílaba dada; identificação da sílaba medial; produção de rima; exclusão silábica; transposição silábica; produção de palavra com o som dado; identificação do fonema inicial; identificação do fonema final; exclusão fonêmica; síntese fonêmica; segmentação fonêmica; transposição fonêmica. Cada acerto equivale a um ponto. $\mathrm{O}$ máximo de pontuação total na tarefa é de 70 pontos, sendo 32 no nível da sílaba, oito no nível da rima e 30 no nível do fonema. Apesar do protocolo realizar a divisão apenas em consciência silábica e consciência fonêmica, as estruturas intra-silábicas foram aqui analisadas como um grupo separado.

\section{b) Avaliação Sintática:}

Módulo de Avaliação das Habilidades Linguísticas (MABILIN) ${ }^{20}$ : utilizado para a avaliação da compreensão de sentenças complexas do Português Brasileiro. Investigou-se o processamento envolvido na compreensão de sentenças ativas reversíveis, passivas reversíveis e irreversíveis, relativas rami- ficadas de sujeito e objeto, interrogativas QU de sujeito e objeto, interrogativas QU+N de sujeito e objeto e relativas encaixadas de sujeito com verbo transitivo (VT) e verbo intransitivo (VI) e objeto (verbo transitivo e intransitivo), sendo a última mais complexa do que as demais orações ${ }^{13}$.

Na prova, o terapeuta deve ler sentenças que possuem as estruturas citadas e o participante deve apontar a figura que combina com o que foi falado. As imagens estão disponíveis em um software de computador. Ao apontar, a figura é selecionada pelo terapeuta e é dado continuidade para a frase seguinte. Ao final, o programa gera um resultado referente ao desempenho da criança em cada tipo de sentença e uma classificação da sua dificuldade em: sem dificuldade, dificuldade expressiva, dificuldade moderada e dificuldade muito acentuada.

Realizaram-se ao total, duas sessões de aproximadamente 40 minutos com cada participante, sendo uma sessão em cada dia, para evitar cansaço ou desatenção por excesso de tarefas. Na primeira sessão foram aplicados o MABILIN e o ANELE 1, enquanto que na segunda sessão foram realizados o CONFIAS, a tarefa de nomeação rápida e o protocolo de memória de trabalho fonológica.

Após a testagem, realizou-se uma análise estatística por meio do teste não paramétrico de Mann-Whitney e do teste paramétrico t-student, com nível de significância (p) de 0,05 , para comparação dos resultados das avaliações das habilidades do processamento sintático e fonológico entre os grupos experimental e controle.

\section{Resultados}

Nesta seção serão apresentados os resultados referentes à comparação do desempenho dos grupos experimental e controle nas tarefas de processamento fonológico e sintático. Inicialmente será realizada uma comparação geral entre todos os participantes do GE $(\mathrm{N}=10)$ e $\mathrm{GC}(\mathrm{N}=20)$. Posteriormente será apresentada a comparação do desempenho em função da idade (G1 e G2).

As Tabelas a seguir ( 1 a 4 ) referem-se aos resultados relativos ao desempenho dos grupos nas habilidades de nomeação rápida, memória de trabalho fonológica, leitura de palavras e pseudopalavras isoladas e consciência fonológica. 
Tabela 1. Comparação do tempo total de realização da tarefa de nomeação rápida entre GE e GC.

\begin{tabular}{lcccccc}
\hline Habilidade & Grupos & Média & Mediana & $\begin{array}{c}\text { Desvio- } \\
\text { Padrão }\end{array}$ & $\begin{array}{c}\text { Teste de Mann- } \\
\text { Whitney } \mathbf{( p )}\end{array}$ & Resultado \\
\hline \multirow{2}{*}{ Tempo total (min) } & GE & 0,81 & 0,72 & 0,31 & $0,001^{*}$ & GE $>$ GC \\
\hline
\end{tabular}

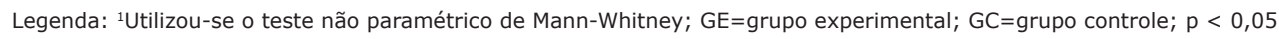

De acordo com a Tabela 1, pode-se observar que as crianças sem queixas de dificuldades de aprendizagem apresentaram uma média de tempo menor na tarefa de nomeação rápida quando comparadas ao grupo de crianças com queixas de dificuldades de aprendizagem. Além disso, pode-se verificar que esta diferença foi estatisticamente significativa $(\mathrm{p}<0,05)$.

Tabela 2. Comparação do número total de acertos na tarefa de memória de trabalho fonológica entre GE e GC.

\begin{tabular}{|c|c|c|c|c|c|c|}
\hline Habilidade & Grupo & Média & Mediana & $\begin{array}{l}\text { Desvio- } \\
\text { Padrão }\end{array}$ & $\begin{array}{c}\text { Teste de Mann- } \\
\text { Whitney }^{1}(p)\end{array}$ & Resultado \\
\hline \multirow{2}{*}{ Memória fonológica total (40) } & GE & 33,2 & 34,0 & 6,0 & \multirow{2}{*}{$0,001 *$} & \multirow{2}{*}{$\mathrm{GE}<\mathrm{GC}$} \\
\hline & GC & 38,7 & 39,0 & 2,0 & & \\
\hline
\end{tabular}

Legenda: ${ }^{1}$ Utilizou-se o teste não paramétrico de Mann-Whitney; GE=grupo experimental; GC=grupo controle; $p<0,05$

Ao analisar a Tabela 2, observa-se que o grupo controle apresentou uma média maior em relação ao número de acertos na tarefa de memória fono- lógica quando comparado ao grupo experimental e essa diferença foi estatisticamente significativa.

Tabela 3. Comparação do número de acertos da leitura total, leitura de palavras quanto a frequência e regularidade e leitura de pseudopalavras entre GE e GC.

\begin{tabular}{|c|c|c|c|c|c|c|}
\hline Habilidade & Grupo & Média & Mediana & $\begin{array}{l}\text { Desvio- } \\
\text { Padrão }\end{array}$ & $\begin{array}{l}\text { Teste de Mann- } \\
\text { Whitney }^{1} \text { (p) }\end{array}$ & Resultado \\
\hline \multirow{2}{*}{ Leitura total (59) } & GE & 23,8 & 22,5 & 20,0 & \multirow{2}{*}{$<0,001^{*}$} & \multirow{2}{*}{$\mathrm{GE}<\mathrm{GC}$} \\
\hline & GC & 54,9 & 54,0 & 2,4 & & \\
\hline \multirow{2}{*}{ Regulares frequentes (10) } & GE & 5,70 & 6,50 & 4,19 & \multirow{2}{*}{$0,005^{*}$} & \multirow{2}{*}{$\mathrm{GE}<\mathrm{GC}$} \\
\hline & GC & 9,80 & 10,00 & 0,41 & & \\
\hline \multirow{2}{*}{ Regulares não frequentes (9) } & GE & 3,90 & 3,50 & 3,41 & \multirow{2}{*}{$0,002 *$} & \multirow{2}{*}{$\mathrm{GE}<\mathrm{GC}$} \\
\hline & GC & 8,45 & 8,00 & 0,51 & & \\
\hline \multirow{2}{*}{ Irregulares frequentes (10) } & GE & 4,30 & 4,50 & 3,86 & \multirow{2}{*}{$<0,001^{*}$} & \multirow{2}{*}{$\mathrm{GE}<\mathrm{GC}$} \\
\hline & GC & 9,60 & 10,00 & 0,60 & & \\
\hline \multirow{2}{*}{ Irregulares não frequentes (10) } & GE & 2,90 & 2,50 & 2,64 & \multirow{2}{*}{$<0,001^{*}$} & \multirow{2}{*}{$\mathrm{GE}<\mathrm{GC}$} \\
\hline & GC & 9,15 & 10,00 & 1,09 & & \\
\hline \multirow{2}{*}{ Pseudopalavras (20) } & GE & 7,00 & 5,50 & 6,68 & \multirow{2}{*}{$<0,001^{*}$} & \multirow{2}{*}{$\mathrm{GE}<\mathrm{GC}$} \\
\hline & $\mathrm{GC}$ & 17,9 & 18,0 & 1,55 & & \\
\hline
\end{tabular}

Legenda: ${ }^{1}$ Utilizou-se o teste não paramétrico de Mann-Whitney; GE=grupo experimental; GC=grupo controle; $p<0,05$ 
Verificou-se, a partir da Tabela 3, que as crianças sem dificuldades de aprendizagem obtiveram uma média maior do número de acertos em comparação com as crianças com queixas de dificuldades de aprendizagem. Essa diferença foi estatisticamente significativa e ocorreu em todas as variáveis analisadas, sendo estas: leitura total, leitura de palavras regulares frequentes, regulares não frequentes, irregulares frequentes, irregulares não frequentes e pseudopalavras.
De acordo com a Tabela 4, em relação à habilidade de consciência fonológica, utilizou-se o teste não paramétrico de Mann-Whitney para a maioria das variáveis, com exceção do Nível do Fonema, para o qual se utilizou o teste paramétrico $t$-student, tendo em vista que foi a única variável não significante na avaliação da Normalidade das variáveis analisadas anteriormente.

Tabela 4. Comparação do desempenho nas habilidades de consciência fonológica entre GE e GC.

\begin{tabular}{|c|c|c|c|c|c|c|}
\hline Habilidade & Grupo & Média & Mediana & $\begin{array}{l}\text { Desvio- } \\
\text { Padrão }\end{array}$ & $\begin{array}{c}\text { Teste de } \\
\text { Mann-Whitney ou } \\
\text { t-student }{ }^{1}(p)\end{array}$ & Resultado \\
\hline \multirow{2}{*}{ Nível da sílaba (32) } & GE & 24,2 & 25,0 & 4,7 & \multirow{2}{*}{$<0,001^{*}$} & \multirow{2}{*}{$\mathrm{GE}<\mathrm{GC}$} \\
\hline & GC & 30,6 & 31,0 & 1,1 & & \\
\hline \multirow{2}{*}{ Nível da rima (8) } & GE & 4,70 & 4,50 & 1,89 & \multirow{2}{*}{$0,001^{*}$} & \multirow{2}{*}{$\mathrm{GE}<\mathrm{GC}$} \\
\hline & GC & 7,15 & 7,50 & 1,04 & & \\
\hline \multirow{2}{*}{ Nível do fonema (30) } & GE & 12,80 & 12,50 & 3,71 & \multirow{2}{*}{$<0,001^{*}$} & \multirow{2}{*}{$\mathrm{GE}<\mathrm{GC}$} \\
\hline & GC & 21,20 & 19,50 & 4,14 & & \\
\hline \multirow{2}{*}{ Consciência fonológica total (70) } & GE & 41,70 & 40,50 & 9,55 & \multirow{2}{*}{$<0,001^{*}$} & \multirow{2}{*}{$\mathrm{GE}<\mathrm{GC}$} \\
\hline & GC & 58,90 & 58,00 & 4,75 & & \\
\hline \multirow{2}{*}{ Síntese silábica (4) } & GE & 4,00 & 4,00 & 0,00 & \multirow{2}{*}{1,000} & \multirow{2}{*}{$\mathrm{GE}=\mathrm{GC}$} \\
\hline & GC & 4,00 & 4,00 & 0,00 & & \\
\hline \multirow{2}{*}{ Segmentação silábica (4) } & GE & 3,70 & 4,00 & 0,67 & \multirow{2}{*}{0,502} & \multirow{2}{*}{$\mathrm{GE}=\mathrm{GC}$} \\
\hline & GC & 3,95 & 4,00 & 0,22 & & \\
\hline \multirow{2}{*}{ Identificação da sílaba inicial (4) } & GE & 2,90 & 3,00 & 0,88 & \multirow{2}{*}{$0,015^{*}$} & \multirow{2}{*}{$\mathrm{GE}<\mathrm{GC}$} \\
\hline & GC & 3,75 & 4,00 & 0,44 & & \\
\hline \multirow{2}{*}{ Identificação da rima (4) } & GE & 3,10 & 3,00 & 0,88 & \multirow{2}{*}{$0,028^{*}$} & \multirow{2}{*}{$\mathrm{GE}<\mathrm{GC}$} \\
\hline & GC & 3,80 & 4,00 & 0,37 & & \\
\hline \multirow{2}{*}{$\begin{array}{l}\text { Produção de palavra com a } \\
\text { sílaba dada (4) }\end{array}$} & GE & 3,60 & 4,00 & 0,70 & \multirow{2}{*}{0,198} & $\mathrm{GE}=\mathrm{GC}$ \\
\hline & GC & 4,00 & 4,00 & 0,00 & & $G$ \\
\hline Identificação da sílaba medial & GE & 3,40 & 4,00 & 0,97 & & \\
\hline & GC & 3,80 & 4,00 & 0,41 & 0,350 & $G E=G C$ \\
\hline Produção de rima (4) & GE & 1,60 & 1,00 & 1,17 & $0.001 *$ & $\mathrm{GE}<\mathrm{GC}$ \\
\hline rivuchao ue tilia (4) & GC & 3,30 & 3,50 & 0,86 & & - \\
\hline Exclusão silábica (8) & GE & 4,40 & 4,50 & 2,37 & $<0,001^{*}$ & $\mathrm{GE}<\mathrm{GC}$ \\
\hline & GC & 7,55 & 8,00 & 0,76 & $-0,001$ & 다 < 30 \\
\hline Transposição silábica (4) & GE & 2,20 & 2,50 & 1,81 & 0,109 & $\mathrm{GE}=\mathrm{GC}$ \\
\hline & GC & 3,50 & 4,00 & 0,61 & & (2) \\
\hline Produção de palavra com o som & GE & 2,80 & 3,00 & 0,92 & $0,008^{*}$ & $\mathrm{GE}<\mathrm{GC}$ \\
\hline dado (4) & GC & 3,70 & 4,00 & 0,57 & 0,000 & UL \\
\hline Identificação do fonema inicial & GE & 3,40 & 4,00 & 0,84 & 0,619 & $\mathrm{GE}=\mathrm{GC}$ \\
\hline$(4)$ & GC & 3,65 & 4,00 & 0,49 & & \\
\hline Identificação do fonema final (4) & GE & 2,00 & 2,00 & 0,94 & $0,005 *$ & $\mathrm{GE}<\mathrm{GC}$ \\
\hline & GC & 3,20 & 3,00 & 0,89 & & \\
\hline Exclusão fonêmica (6) & GE & 2,00 & 2,00 & 1,56 & $<0,001 *$ & $\mathrm{GE}<\mathrm{GC}$ \\
\hline & $\begin{array}{l}\text { GC } \\
\text { GE }\end{array}$ & $\begin{array}{l}4,95 \\
1,40\end{array}$ & $\begin{array}{l}5,00 \\
1,50\end{array}$ & $\begin{array}{l}0,69 \\
0,70\end{array}$ & & \\
\hline Síntese fonêmica (4) & $\mathrm{GC}$ & $\begin{array}{l}1,40 \\
2,80\end{array}$ & $\begin{array}{l}1,50 \\
3,00\end{array}$ & 0,89 & $<0,001 *$ & $\mathrm{GE}<\mathrm{GC}$ \\
\hline Segmentação fonêmica (4) & GE & 0,90 & 0,50 & 1,20 & 0.559 & \\
\hline & GC & 1,35 & 1,00 & 1,53 & כנכ, & SL- - S \\
\hline Transposição fonêmica (4) & GE & 0,30 & 0,00 & 0,67 & $0,022 *$ & $\mathrm{GE}<\mathrm{GC}$ \\
\hline & GC & 1,55 & 1,50 & 1,43 & & \\
\hline
\end{tabular}

Legenda: ${ }^{1}$ Utilizou-se o teste não paramétrico de Mann-Whitney para a maioria das

variáveis, com exceção do nível do fonema, para o qual utilizou-se o teste paramétrico $t$-student; GE=grupo experimental; GC=grupo controle; $\mathrm{p}<0,05$ 
Pode-se verificar, de acordo com a Tabela 4, que houve diferença estatística significativa em relação ao desempenho no nível da sílaba, nível da rima, nível do fonema, consciência fonológica total, identificação da sílaba inicial, identificação de rima, produção de rima, exclusão silábica, produção de palavra com o som dado, identificação do fonema final, exclusão, síntese e transposição fonêmica, com um maior número de acertos do grupo controle em comparação com o grupo experimental.
As demais variáveis (síntese silábica, segmentação silábica, produção de palavra com a sílaba dada, identificação da sílaba inicial, transposição silábica, identificação do fonema inicial e segmentação fonêmica) não apresentaram diferença estatística significativa no desempenho entre os grupos.

Serão apresentados os resultados relativos ao desempenho dos grupos na habilidade de compreensão sintática de diferentes custos computacionais.

Tabela 5. Comparação do desempenho na compreensão de sentenças de diferentes custos computacionais entre GE e GC.

\begin{tabular}{|c|c|c|c|c|c|c|}
\hline Habilidade & Grupo & Média & Mediana & $\begin{array}{l}\text { Desvio- } \\
\text { Padrão }\end{array}$ & $\begin{array}{l}\text { Teste de Mann- } \\
\text { Whitney }^{1}(p)\end{array}$ & Resultado \\
\hline \multirow{2}{*}{ Ativas (8) } & GE & 7,7 & 8,0 & 0,5 & \multirow{2}{*}{0,880} & \multirow{2}{*}{$\mathrm{GE}=\mathrm{GC}$} \\
\hline & GC & 7,7 & 8,0 & 0,6 & & \\
\hline \multirow{2}{*}{ Passivas irreversíveis (8) } & GE & 7,9 & 8,0 & 0,3 & \multirow{2}{*}{1,000} & \multirow{2}{*}{$\mathrm{GE}=\mathrm{GC}$} \\
\hline & GC & 7,9 & 8,0 & 0,3 & & \\
\hline \multirow{2}{*}{ Passivas reversíveis (8) } & GE & 7,20 & 7,50 & 1,03 & \multirow{2}{*}{0,746} & \multirow{2}{*}{$\mathrm{GE}=\mathrm{GC}$} \\
\hline & GC & 7,15 & 7,00 & 0,81 & & \\
\hline \multirow{2}{*}{$\begin{array}{l}\text { Relativas ramificadas de sujeito } \\
\text { (8) }\end{array}$} & GE & 7,90 & 8,00 & 0,32 & \multirow{2}{*}{0,530} & \multirow{2}{*}{$\mathrm{GE}=\mathrm{GC}$} \\
\hline & GC & 7,75 & 8,00 & 0,44 & & \\
\hline \multirow{2}{*}{$\begin{array}{l}\text { Relativas ramificadas de objeto } \\
\text { ( } 8 \text { ) }\end{array}$} & GE & 6,90 & 7,00 & 1,20 & \multirow{2}{*}{0,397} & \multirow{2}{*}{$\mathrm{GE}=\mathrm{GC}$} \\
\hline & GC & 7,40 & 7,00 & 0,60 & & \\
\hline \multirow{2}{*}{ Interrogativas QU de sujeito (8) } & GE & 8,00 & 8,00 & 0,00 & \multirow{2}{*}{1,000} & \multirow{2}{*}{$\mathrm{GE}=\mathrm{GC}$} \\
\hline & GC & 8,00 & 8,00 & 0,00 & & \\
\hline \multirow{2}{*}{ Interrogativas QU de objeto (8) } & GE & 7,60 & 8,00 & 0,52 & \multirow{2}{*}{0,198} & \multirow{2}{*}{$\mathrm{GE}=\mathrm{GC}$} \\
\hline & GC & 7,90 & 8,00 & 0,31 & & \\
\hline \multirow{2}{*}{$\begin{array}{l}\text { Interrogativas } \mathrm{QU}+\mathrm{N} \text { de sujeito } \\
\text { (8) }\end{array}$} & GE & 7,70 & 8,00 & 0,48 & \multirow{2}{*}{0,619} & \multirow{2}{*}{$\mathrm{GE}=\mathrm{GC}$} \\
\hline & GC & 7,75 & 8,00 & 0,64 & & \\
\hline \multirow{2}{*}{$\begin{array}{l}\text { Interrogativas } \mathrm{QU}+\mathrm{N} \text { de objeto } \\
\text { (8) }\end{array}$} & GE & 7,00 & 7,00 & 0,94 & \multirow{2}{*}{0,286} & \multirow{2}{*}{$\mathrm{GE}=\mathrm{GC}$} \\
\hline & GC & 7,35 & 8,00 & 0,93 & & \\
\hline \multirow{2}{*}{$\begin{array}{l}\text { Relativas encaixadas de sujeito } \\
\text { VT }\end{array}$} & GE & 7,30 & 8,00 & 1,25 & \multirow{2}{*}{0,983} & \multirow{2}{*}{$\mathrm{GE}=\mathrm{GC}$} \\
\hline & GC & 7,50 & 8,00 & 0,69 & & \\
\hline \multirow{2}{*}{$\begin{array}{l}\text { Relativas encaixadas de objeto } \\
\text { VT ( } 8 \text { ) }\end{array}$} & GE & 6,10 & 6,50 & 2,08 & \multirow{2}{*}{0,350} & $\mathrm{GE}=\mathrm{GC}$ \\
\hline & GC & 6,65 & 8,00 & 1,84 & & $G L=G$ \\
\hline Relativas encaixadas de sujeito & GE & 6,80 & 7,00 & 1,40 & 0,267 & $\mathrm{GE}=\mathrm{GC}$ \\
\hline VI $(8)$ & GC & 7,45 & 8,00 & 0,76 & & \\
\hline Relativas encaixadas de objeto & GE & 6,30 & 6,50 & 1,49 & 0,286 & $\mathrm{GE}=\mathrm{GC}$ \\
\hline VI (8) & GC & 6,90 & 8,00 & 1,37 & & (l一) \\
\hline
\end{tabular}

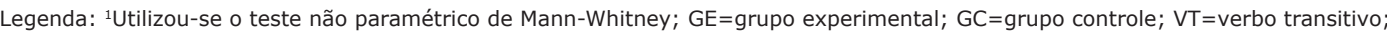
$\mathrm{VI}=$ verbo intransitivo; $\mathrm{p}<0,05$ 
Pode-se observar, a partir da análise da Tabela 5 , que nenhuma das variáveis relativas à compreensão sintática apresentou diferença estatística significativa, tendo em vista que todas obtiveram valores de $\mathrm{p}>0,05$.

Apesar de não haver diferença estatística significativa entre os grupos em relação às variáveis de processamento sintático, pôde-se observar que houve uma diferença na média de acertos em relação a algumas sentenças entre os grupos.

Dessa forma, para análise do processamento sintático optou-se por realizar uma comparação da compreensão de estruturas sintáticas, entre os grupos, em relação às médias de desempenho em que foi observada diferença $\geq 0,50$ entre as médias de acertos do grupo controle (crianças sem queixas de dificuldades) e experimental (crianças com queixas de dificuldades). Foram analisadas comparativamente as seguintes sentenças: relativas ramificadas de objeto, relativas encaixadas de objeto com verbo transitivo, relativas encaixadas de sujeito com verbo intransitivo e relativas encaixadas de objeto com verbo intransitivo.

Pode-se observar, a partir da Tabela 5, que as crianças com queixas de dificuldades de aprendi- zagem obtiveram um desempenho inferior quando comparadas com crianças sem queixas em todas as variáveis analisadas, sendo elas: sentenças relativas ramificadas de objeto, relativas encaixadas de objeto com verbo transitivo, relativas encaixadas de sujeito com verbo intransitivo, relativas encaixadas de objeto com verbo intransitivo.

Para análise mais detalhada do desempenho de cada grupo, os participantes foram divididos em dois subgrupos por faixa etária, sendo o primeiro composto por crianças de sete a nove anos (G1) e o segundo por crianças de 10 e 11 anos (G2). Assim, será realizada uma comparação entre os participantes dos grupos experimental e controle que possuam a mesma faixa etária (intergrupos) e uma comparação entre participantes do mesmo grupo de diferentes faixas etárias (intragrupo). O mesmo será feito em relação às seguintes variáveis: memória de trabalho fonológica, nomeação rápida, leitura de palavras e pseudopalavras isoladas, consciência fonológica e compreensão de estruturas sintáticas, as quais estão representadas nas Figuras abaixo (1 a 5).

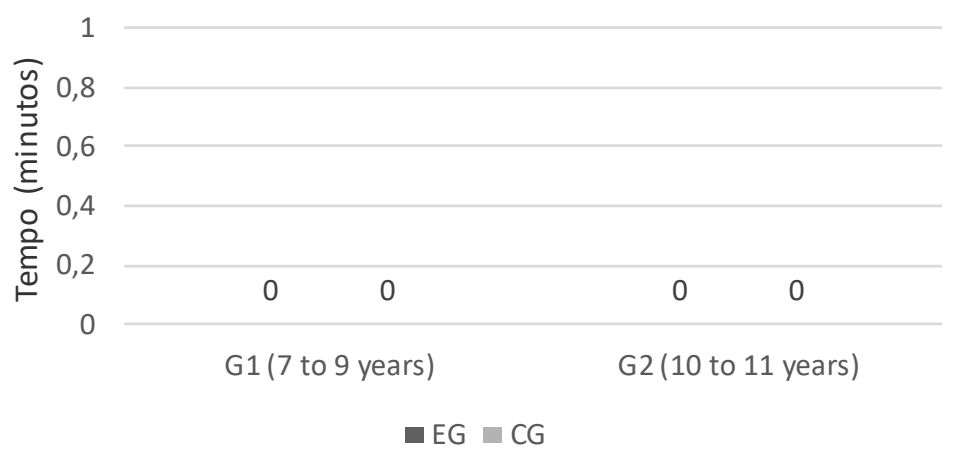

Legenda: $\mathrm{GE}=$ grupo experimental; $\mathrm{GC}=$ grupo controle; $\mathrm{G} 1=$ grupo $1 ; \mathrm{G} 2=$ grupo 2

Figura 1. Comparação da média de desempenho na nomeação rápida entre GE e GC por faixa etária.

Verifica-se a partir da Figura 1, que para os dois grupos de idade (G1 e G2), os participantes com alterações de aprendizagem necessitaram de mais tempo para realização da tarefa quando comparados aos participantes sem queixas de dificuldades de aprendizagem. Porém, apenas no grupo de crianças com dificuldades de aprendizagem houve diferença expressiva em relação à faixa etária, demonstrando melhor desempenho de crianças mais velhas (G2) em comparação às crianças mais novas (G1). 


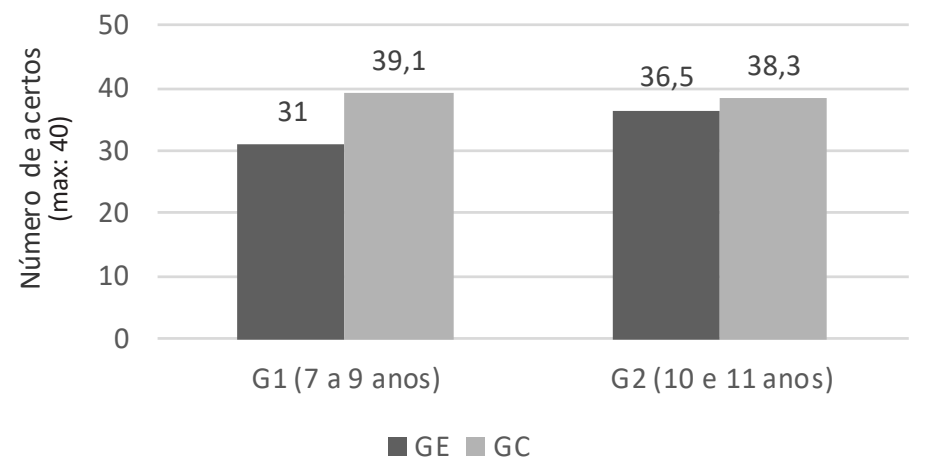

Legenda: $\mathrm{GE}=$ grupo experimental; $\mathrm{GC}=$ grupo controle; $\mathrm{G} 1=$ grupo 1; G2=grupo 2; máx.=máximo

Figura 2. Comparação da média de desempenho na memória de trabalho fonológica entre GE e GC por faixa etária.

Ao analisar a Figura 2, observa-se melhor desempenho de participantes sem queixas de dificuldades de aprendizagem em relação aos participantes com queixas de dificuldades que possuam a mesma faixa etária. Ao contrapor os participantes do mesmo grupo (GE ou GC) de diferentes idades, observa-se que houve diferença relevante apenas para as crianças com alterações de aprendizagem, os quais demonstraram melhores resultados para crianças mais velhas $(\mathrm{G} 2)$.

Para verificação do desempenho de leitura por idade, optou-se por realizar a análise da leitura de palavras apenas em relação à regularidade. Portanto, a variável de frequência, assim como a de extensão do estímulo, não foi abordada nesta parte do estudo. Os dados estão expostos na Figura 3, a seguir.

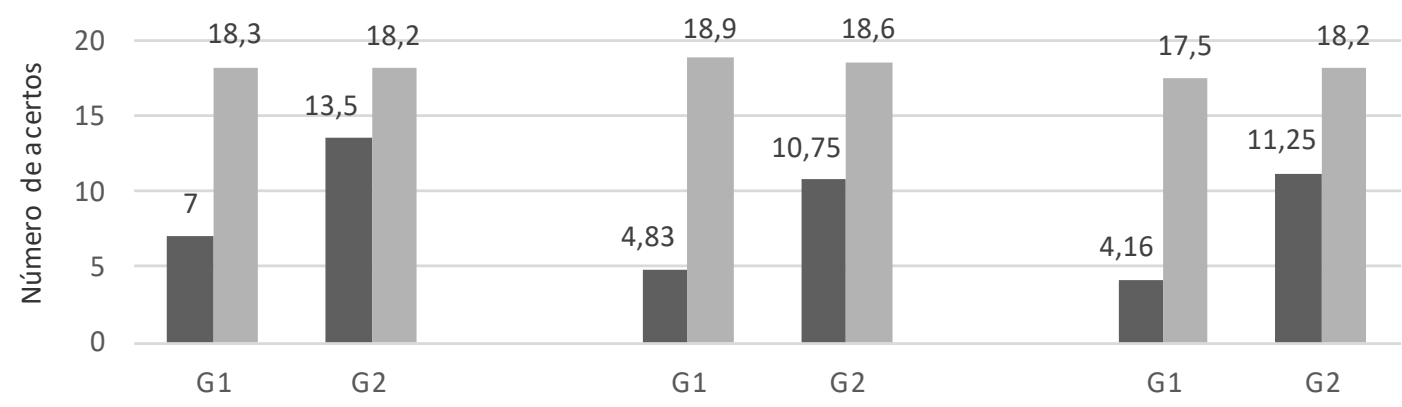

Palavras regulares

Palavrasirregulares Pseudopalavras..

$\square \mathrm{GE} \square \mathrm{GC}$

Legenda: $\mathrm{GE}=$ grupo experimental; $\mathrm{GC}=$ grupo controle; $\mathrm{G} 1=$ grupo 1; $\mathrm{G} 2=$ grupo 2; máx.=máximo

Figura 3. Comparação da média de desempenho na leitura de palavras e pseudopalavras isoladas entre GE e GC por faixa etária.

A Figura 3 demonstra superioridade de desempenho das crianças sem queixas de dificuldades de aprendizagem em relação àquelas com queixas quanto à leitura de palavras regulares, palavras irregulares e pseudopalavras, para todos os grupos de idade. Porém, apenas o grupo de participantes com queixas de dificuldades de aprendizagem apresentou diferença de desempenho em relação a idade, demonstrando melhores resultados de crianças mais velhas $(\mathrm{G} 2)$. 
$\mathrm{Na}$ análise da habilidade de consciência fonológica por idade, foram abordados apenas os níveis da sílaba, da rima e do fonema como um todo, sem considerar as tarefas individuais de cada nível, tendo em vista o grande número das mesmas. Os resultados estão representados na Figura 4, abaixo.

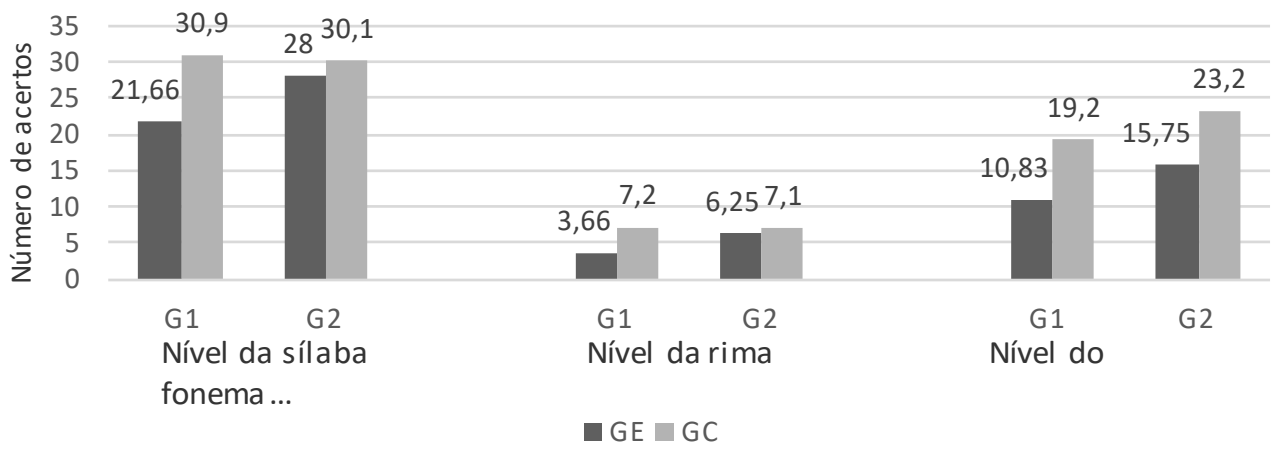

Legenda: $\mathrm{GE}=$ grupo experimental; GC=grupo controle; G1= grupo 1; G2=grupo 2; máx.=máximo

Figura 4. Comparação da média de desempenho na consciência fonológica entre GE e GC por faixa etária

Ao observar a Figura 4, verifica-se menor desempenho médio nos níveis da sílaba, rima e fonema de participantes com queixas de aprendizagem comparativamente aos participantes sem queixas em todos os grupos de idade. Ao analisar os resultados das crianças com queixas de dificuldades de aprendizagem observa-se diferença relevante entre as faixas etárias em todas as variáveis, enquanto as crianças sem dificuldades expressam diferença de desempenho em função da idade apenas no nível do fonema. Nesses casos, as crianças mais velhas (G2) apresentaram melhor desempenho quando comparadas às mais novas (G1).

Para análise mais detalhada do desempenho na compreensão de sentenças por idade, optou-se por comparar apenas aquelas em que houve diferença $\geq$ 0,5 em relação às médias de desempenho de GE e de GC, devido ao grande número de variáveis. Os dados estão dispostos na Figura 5, abaixo.

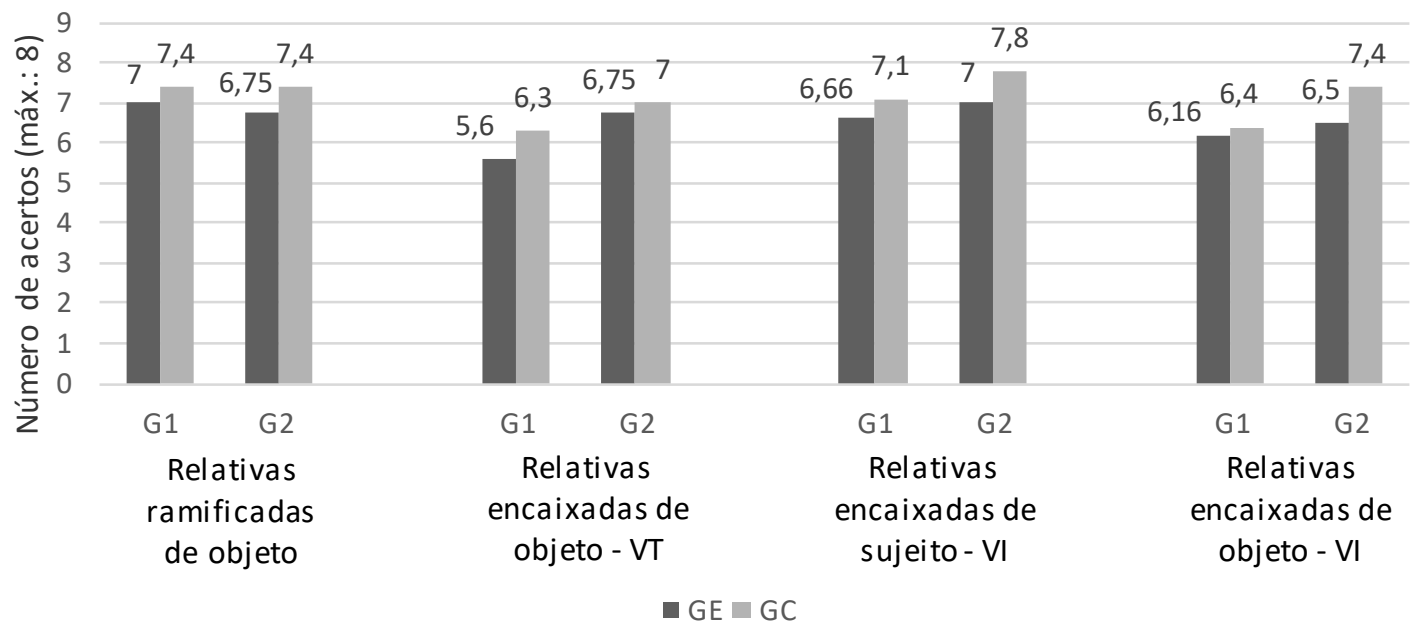

Legenda: $\mathrm{GE}=$ grupo experimental; $\mathrm{GC}=$ grupo controle; $\mathrm{G} 1=$ grupo $1 ; \mathrm{G} 2=$ grupo $2 ; \mathrm{VT}=$ verbo transitivo; $\mathrm{VI}=$ verbo intransitivo; máx.=máximo

Figura 5. Comparação da média de desempenho na compreensão sintática entre GE e GC por faixa etária. 
A Figura 5 demonstra que as crianças mais novas (G1) dos grupos com e sem queixas de dificuldades de aprendizagem apresentaram diferença considerável $(\geq 0,5)$ de desempenho na compreensão de sentenças relativas encaixadas de objeto com verbo transitivo e relativas encaixadas de sujeito com verbo intransitivo, sendo maiores os resultados das crianças sem queixas de dificuldades. Já as crianças mais velhas $(\mathrm{G} 2)$ desses grupos diferiram de forma relevante na compreensão de relativas ramificadas de objeto, relativas encaixadas de sujeito com verbo intransitivo e relativas encaixadas de objeto com verbo intransitivo, também com melhor desempenho de crianças sem queixas. Além disso, observa-se que o grupo experimental (crianças com queixas de dificuldades de aprendizagem) obteve diferença de desempenho em função da idade apenas na compreensão de relativas encaixadas de objeto com verbo transitivo, enquanto o grupo controle (crianças sem queixas de dificuldades de aprendizagem) obteve para relativas encaixadas de objeto com verbo transitivo, relativas encaixadas de sujeito com verbo intransitivo e relativas encaixadas de objeto com verbo intransitivo. Em ambos os casos, as crianças de 10 e 11 anos demonstraram melhores desempenhos

É importante destacar que, na comparação entre os grupos por idade, não foi possível aplicar um teste estatístico devido ao número reduzido de participantes em cada subgrupo (G1 e G2), por isso a análise foi feita a partir da comparação das médias de desempenho.

\section{Discussão}

De acordo com os resultados encontrados, pode-se verificar que, de forma geral, os participantes com queixas de dificuldades de aprendizagem apresentaram um desempenho inferior na maioria das habilidades fonológicas investigadas, quando comparadas ao grupo controle.

Na avaliação da nomeação rápida, observou-se diferença estatística significativa ao comparar o desempenho dos grupos controle e experimental. Verificou-se que o GE (crianças com queixas de dificuldades de aprendizagem) necessitou de mais tempo para realização da tarefa quando comparado ao GC (crianças sem queixas de dificuldades de aprendizagem). Em relação às médias de desempenho, ambos os grupos obtiveram resultados classificados como superiores segundo os critérios de normalidade do Protocolo de Avaliação das Habilidades Cognitivo Linguísticas ${ }^{16}$. Entretanto, os participantes com queixas de dificuldades apresentaram pior desempenho quando comparados com aqueles sem queixas, tendo em vista os valores das médias. A respeito dos resultados individuais, observou-se que a maioria dos participantes do GE $(60 \%)$ realizou a atividade em mais de 0,66 minutos, tempo máximo obtido pelo grupo controle, o que sugere maior dificuldade na habilidade de velocidade de processamento da informação neste grupo.

Os resultados obtidos neste estudo estão de acordo com pesquisas que investigaram o desempenho de crianças com dificuldades ou transtornos de aprendizagem em tarefas que envolviam a nomeação automática rápida. Essas crianças apresentam alterações de velocidade de processamento, que inclui, entre outras habilidades, a capacidade de processar símbolos visuais rapidamente, imprescindível para a leitura ${ }^{21}$.

Em relação à memória de trabalho fonológica, os escolares com queixas de dificuldades de aprendizagem apresentaram desempenho inferior quando comparados aos participantes sem queixas e a diferença entre os grupos foi estatisticamente significativa. Os resultados obtidos concordam com pesquisas sobre o tema, que indicam que alterações de memória de trabalho podem ser consideradas como uma das características de crianças com alterações de aprendizagem ${ }^{22}$.

Os dados desta pesquisa apresentaram resultados inferiores em relação à leitura de palavras e pseudopalavras para as crianças do grupo experimental em relação ao grupo controle para todas as variáveis. Estudos a respeito do desempenho de escolares com dificuldades de aprendizagem na leitura de palavras e pseudopalavras demonstram alterações quanto à conversão grafema-fonema, ou seja, comprometimento de uso, principalmente, da rota fonológica por parte dos mesmos ${ }^{23,24}$. A diferença de desempenho entre os grupos neste estudo foi estatisticamente significativa para todas as variáveis avaliadas, porém ocorreu de forma mais expressiva para a leitura de pseudopalavras, indicando comprometimento na rota fonológica, como encontrado pelos autores acima citados. Porém, essas crianças também apresentaram dificuldades relevantes na leitura de palavras irregulares, o que indica também alteração na rota lexical.

Outro fator que demonstrou diferença em relação ao desempenho de cada grupo foi a fre- 
quência das palavras, tendo em vista que a leitura de palavras regulares e irregulares frequentes foi mais fácil para ambos os grupos quando comparadas àquelas não frequentes, o que também ocorreu em outras pesquisas ${ }^{7}$. O desempenho dos escolares com queixas de dificuldades de aprendizagem nas tarefas de leitura pode ser correlacionado com o desempenho da avaliação da nomeação automática rápida, já que algumas pesquisas demonstram a influência dessa para a habilidade leitora, como citado anteriormente $^{21}$. A leitura de palavras irregulares, por exemplo, de acordo com a hipótese de alguns autores, associa-se à nomeação seriada rápida de estímulos, pois ambas as tarefas envolvem o aprendizado de relações símbolo-nome arbitrárias, o que pode justificar os resultados inferiores das crianças com queixas de dificuldades de aprendizagem (GE) nas duas atividades ${ }^{25}$.

Da mesma forma, os resultados das habilidades de consciência fonológica demonstraram que as crianças com queixas de dificuldades de aprendizagem (GE) apresentaram desempenho inferior às crianças sem dificuldades (GC). A diferença foi estatisticamente significativa na consciência fonológica total e nos níveis da sílaba, rima e fonema, assim como nas tarefas individuais de identificação da sílaba inicial, identificação da rima, produção de rima, exclusão silábica, produção de palavra com o som dado, identificação do fonema final, exclusão, síntese e transposição fonêmica. Nas demais variáveis da habilidade de consciência fonológica não houve diferença estatística significativa entre o desempenho dos grupos. Observou-se, a partir dos resultados, que as crianças com queixa de dificuldades de aprendizagem apresentaram diferença estatística significativa em relação ao grupo controle em praticamente todas as tarefas envolvendo o nível do fonema.

Apesar do desempenho de GE ter sido inferior ao de GC para todas as variáveis citadas, observou-se que no nível do fonema os participantes sem queixas de dificuldades de aprendizagem não apresentaram resultados próximos à pontuação máxima, ao contrário do que ocorreu para as demais variáveis. $\mathrm{O}$ fato sugere que dificuldades maiores em unidades fonêmicas não são exclusivas de escolares com alterações de aprendizagem, o que pode ser explicado pela ausência de instrução formal do princípio alfabético de forma a abordar e estimular o fonema e a consciência fonêmica ${ }^{24}$.
Pesquisas que avaliam a consciência fonológica em crianças com dificuldade ou transtorno de aprendizagem também demonstram desempenhos inferiores dessas crianças em relação àquelas sem dificuldades na maioria das habilidades avaliadas, o que confirma os resultados obtidos neste estu$\mathrm{do}^{24,25}$. Além disso, muitos autores correlacionam as alterações fonológicas com os déficits de leitura desses escolares, tendo em vista que as habilidades de refletir e manipular as unidades fonológicas são importantes para a aprendizagem da correlação fonema-grafema e consequentes decodificação e codificação necessárias para a leitura e escrita ${ }^{5}$.

A consciência fonológica relaciona-se, também, com a habilidade de memória de trabalho fonológica, tendo em vista que para realizar as atividades de manipulação das unidades fonológicas é necessário reter as informações nessa memória para posterior realização da tarefa ${ }^{26}$. Por exemplo, na atividade de síntese fonêmica, a criança deve utilizar a memória de trabalho fonológica para armazenar temporariamente todos os fonemas ditos pelo avaliador, para poder sintetizá-los e dizer qual palavra formam. Da mesma forma, quanto melhor o desenvolvimento e aprimoramento de habilidades de consciência fonológica, maior a probabilidade de reter as informações na memória de curto prazo para realização das atividades propostas ${ }^{27}$ Tais fatores podem ter influenciado nos resultados das avaliações deste estudo, que demonstraram desempenho inferior de crianças com queixas de dificuldades de aprendizagem tanto em tarefas de memória de trabalho fonológica, como em consciência fonológica.

As dificuldades de aprendizagem podem ocorrer de forma primária (causada por fatores extrínsecos como condições psicológicas, familiares ou pedagógicas), e de forma secundária a outras alterações (comprometimento sensorial, neurológico, psiquiátrico, mental ou síndromes). Já os transtornos de aprendizagem, nos quais as crianças também apresentam baixo desempenho escolar, ocorrem por causas intrínsecas (alterações de origem neurobiológica) ${ }^{28}$. Além disso, os transtornos de aprendizagem podem ocorrer concomitantemente ou em decorrência de outras alterações de linguagem, como no caso de crianças com Transtorno do Desenvolvimento da Linguagem (TDL). Portanto, algumas crianças com TDL podem também apresentar alterações de aprendizagem, e essas duas condições ocorrem diante da ausência de compro- 
metimentos neurológicos, cognitivos, intelectuais e sensoriais ${ }^{13}$. Como estudos a respeito do TDL $^{29}$ indicam que essas crianças apresentam dificuldades no processamento sintático, indivíduos com alterações de aprendizagem que apresentam, além do comprometimento fonológico, déficits também no processamento sintático de orações de alto custo computacional, poderiam apresentar TDL.

Os resultados da avaliação de compreensão sintática deste estudo demonstraram que não houve diferença estatística significativa entre o desempenho das crianças com e sem queixas de dificuldades de aprendizagem para nenhuma das variáveis analisadas. Porém, a partir da análise das médias de desempenho, observou-se diferença mais expressiva $(\geq 0,5)$ entre os grupos em relação à compreensão de sentenças relativas ramificadas de objeto, relativas encaixadas de objeto com verbo transitivo, relativas encaixadas de sujeito com verbo intransitivo e relativas encaixadas de objeto com verbo intransitivo.

A inexistência de diferença estatística significativa entre o desempenho dos grupos controle e experimental na compreensão sintática e a ausência no comprometimento sintático das crianças com dificuldades de aprendizagem neste estudo não fornece dados conclusivos a respeito de um possível TDL, pois para dados mais robustos também é necessário avaliar a produção de sentenças de alto custo computacional, como também aumentar o número participantes da amostra.

Em relação à comparação do desempenho dos grupos experimental e controle por idade, não foi possível realizar uma análise estatística devido ao número reduzido de participantes de cada grupo (G1 e G2). Por isso, a análise foi feita a partir das médias de desempenho das crianças com e sem queixas de dificuldades de aprendizagem. Para verificar se essa diferença é estatisticamente significativa sugere-se aumentar o número de participantes em cada faixa etária.

$\mathrm{Na}$ avaliação do processamento fonológico, verificou-se melhores resultados dos participantes de 10 e 11 anos (G2) do grupo experimental em relação às crianças de sete a nove anos (G1) do mesmo grupo para as habilidades de nomeação rápida, memória de trabalho fonológica, leitura de palavras e pseudopalavras e consciência fonológica. Já os participantes do grupo controle não apresentaram diferença nos resultados em função da idade para essas habilidades, sendo o desempenho superior para as duas faixas etárias. $\mathrm{O}$ fato sugere que crianças sem dificuldades de aprendizagem desenvolvem as habilidades fonológicas antes daquelas com dificuldades e por isso, crianças de sete a nove anos já demonstram resultados próximos à pontuação máxima, enquanto crianças com dificuldades aproximam-se dessa pontuação entre 10 e 11 anos, e ainda assim não a atingem completamente.

Especificamente na habilidade de consciência fonológica, mesmo as crianças mais velhas (10 e 11 anos) do grupo experimental não apresentaram desempenho satisfatório em relação às habilidades fonêmicas, pois essa está intrinsicamente relacionada à aquisição do princípio alfabético e o domínio da leitura e escrita, que não estavam completamente desenvolvidos por apresentarem alterações de aprendizagem ${ }^{9}$.

Entretanto, essa diferença entre as faixas etárias não ocorreu de forma expressiva na avaliação do processamento sintático. Observou-se que as únicas estruturas que apresentaram diferenças de desempenho considerável $(\geq 0,5)$ em função da idade em ambos os grupos foram as orações encaixadas de objeto com verbo transitivo. De forma geral, os resultados sugerem que essas orações são mais dificultosas para as crianças, independentemente da ausência ou presença de dificuldades de aprendizagem. Além disso, indicam que a idade não é um fator tão influente no desenvolvimento de habilidades de compreensão sintática, o que concorda com autores que demonstraram que a compreensão de sentenças de alto custo computacional, principalmente as relativas encaixadas de objeto, são de difícil compreensão tanto para crianças como para adultos ${ }^{30}$.

\section{Conclusão}

Os dados desta pesquisa demonstraram que os participantes com queixas de dificuldades de aprendizagem apresentaram desempenho inferior em relação aos participantes sem queixas de aprendizagem para a maioria das habilidades do processamento fonológico avaliadas, sendo estas: nomeação automática rápida de figuras, memória de trabalho fonológica, leitura de palavras e pseudopalavras isoladas e consciência fonológica.

Observou-se que os resultados do processamento fonológico variaram em função da idade apenas para o grupo de escolares com queixas de dificuldades, ao apresentarem melhores desempe- 
nhos em crianças mais velhas (10 e 11 anos) em relação às mais novas (sete a nove anos) em todas as variáveis. Já o grupo de crianças sem queixas de aprendizagem demonstrou ter desenvolvido as habilidades fonológicas antes daquelas com dificuldades de aprendizagem, tendo em vista que os resultados das crianças de sete a nove anos se assemelharam aos de crianças de 10 e 11 anos.

$\mathrm{Na}$ habilidade de consciência fonológica, observou-se que o grupo experimental apresentou piores desempenhos em relação ao grupo controle em praticamente todas as tarefas envolvendo o nível do fonema, e mesmo as crianças mais velhas (10 e 11 anos), não apresentaram desempenho satisfatório nessas habilidades. O fato pode ser atribuído ao processo de leitura e escrita que não está completamente desenvolvido nessas crianças, tendo em vista que as mesmas apresentam dificuldades nesse percurso por apresentarem dificuldades de aprendizagem.

Em relação ao processamento sintático, conclui-se que apesar de não haver diferença estatisticamente significativa entre o desempenho de crianças com e sem queixas de dificuldades de aprendizagem, observou-se piores resultados para a compreensão de sentenças relativas quando comparadas aos demais tipos de sentenças e também piores desempenhos de relativas de objeto em relação às de sujeito, devido ao maior custo computacional que exigem, dificultando seu processamento. Além disso, notou-se que o fator idade não foi determinante para um melhor desempenho na compreensão das sentenças.

Em suma, os participantes com queixas de dificuldades de aprendizagem demonstraram alterações estatisticamente significativas apenas em relação ao processamento fonológico. Porém os dados não permitem concluir que todas as crianças com dificuldades de aprendizagem não apresentem alterações de processamento sintático, devido ao número reduzido de sujeitos da amostra. Por isso, recomenda-se aumentar o número de participantes dos grupos experimental e controle e, consequentemente, o número de participantes de cada faixa etária. Sugere-se também a realização de estudos que enfocam a produção de sentenças complexas do Português Brasileiro e pesquisas longitudinais a respeito de crianças com Transtorno do Desenvolvimento da Linguagem, a fim de verificar a incidência de alterações de aprendizagem concomitantes ou decorrentes do TDL.

\section{Referências Bibliográficas}

1. Sisto FF. Dificuldades de aprendizagem. In: Sisto FF, Boruchovitch E, Fini LDT, Brenelli RP, Martinelli SC (Orgs.). Dificuldades de aprendizagem no contexto psicopedagógico. $2^{\mathrm{a}}$ ed. Petrópolis: Vozes; 2001. p. 19-39.

2. Serafin ECB, Pereira AS. Dificuldades de aprendizagem no contexto das produções acadêmicas brasileiras (2001-2011). Revista Roteiro [periódico na Internet]. 2015 Jul-Dez [acesso em 7 Ago 2018]; 40(2):419-36. Disponível em: http://editora. unoesc.edu.br/index.php/roteiro/article/view/6887/4941

3. Gonçalves-Guedim TF, Capelatto IV, Salgado-Azoni CA, Ciasca SM, Crenitte PAP. Desempenho do processamento fonológico, leitura e escrita em escolares com transtorno de déficit de atenção e hiperatividade. Rev. CEFAC. [periódico na Internet]. 2017 Mar-Abr [acesso em 1 Ago 2018]; 19(2):242-52. Disponível em: http://www.scielo.br/scielo.php?script=sci arttext\&pid=S1516-18462017000200242\&1 ng=en

4. Wagner RK, Torgesen JK. The nature of phonological processing and its causal role in the acquisition of reading skills. Psychol. bull. [periódico na Internet]. 1987 Mar [acesso em 7 Ago 2018]; 101(2):192-212. Disponível em: http://psycnet-apaorg.ez24.periodicos.capes.gov.br/fulltext/1987-18273-001.htm

5. Vellutino FR, Fletcher JM, Snowling MJ, Scanlon DM. Specific reading disability (dyslexia): what have we learned in the past four decades? J. child psychol. psychiatry allied discipl. [periódico na Internet]. 2004 Jan [acesso em 7 Ago 2018]; 45(1): 2-40. Disponível em: https://onlinelibrary.wiley. com/doi/full/10.1046/j.0021-9630.2003.00305.x

6. Silva JBL, Moura RJ, Wood G, Haase VG. Processamento Fonológico e Desempenho em Aritmética: Uma Revisão da Relevância para as Dificuldades de Aprendizagem. Temas psicol. (Online). [periódico na Internet]. 2015 Jul [acesso em 1 Ago 2018]; 23(1):157-73. Disponível em: http://pepsic. bvsalud.org/scielo.php?script $=$ sci_arttext\&pid=S1413389X2015000100012

7. Barbosa T, Rodrigues CC, Toledo-Piza CM, Navas ALGP, Bueno O F A. Perfil de linguagem e funções cognitivas em crianças com dislexia falantes do Português Brasileiro. CoDAS. [periódico na Internet]. 2015 Mai [acesso em 6 Ago 2018]; 27(6): 565-74. Disponível em: http://www.scielo.br/pdf/codas/ v27n6/2317-1782-codas-27-06-00565.pdf

8. Plaza M, Cohen H. The interaction between phonological processing, syntactic awareness, and naming speed in the reading and spelling performance of first-grade children. Brain cogn. [periódico na Internet]. 2003 Mai [acesso em 7 Ago 2018]; 53(1): 287-92. Disponível em: https://wwwsciencedirect.ez24.periodicos.capes.gov. br/science/article/pii/ S0278262603001283?via\%3Dihub

9. Baddeley AD, Hitch G. Working memory. Curr. biol. [periódico na Internet]. $2010 \mathrm{Fev}$ [acesso em 7 Ago 2018]; 20(4):136-40. Disponível em: https://www-sciencedirect. ez24.periodicos.capes.gov.br/science/article/pii/ S0960982209021332?via\%3Dihub

10. Santamaria VL, Leitão PB, Assencio-Ferreira VJ. A consciência fonológica no processo de alfabetização. Rev. CEFAC. [periódico na Internet]. 2004 Jul-Set [acesso em 8 Ago 2018]; 6(3): 237-41. Disponível em: http://www.revistacefac. com.br/fasciculo.php?url=1\&form=edicoes/revista/revista63/ Artigo\%201.pdf 
11. Capovilla AGS, Capovilla FC. Efeitos do treino de consciência fonológica em crianças com baixo nível socioeconômico. Psicol. reflex. crit. [periódico na Internet]. 2000 [acesso em 8 Ago 2018]; 13(1): 07-24. Disponível em: http://www.scielo.br/scielo.php?script=sci_arttext\&pid $=\mathrm{S} 0102-79722000000100003 \&$ lng $=$ en $\& \mathrm{nrm}=\mathrm{iso} \& \mathrm{t} \operatorname{lng}=\mathrm{pt}$

12. Silva APC, Capellini SA. Desempenho de escolares com dificuldades de aprendizagem em um programa de intervenção com a consciência fonológica. Psicopedagogia. [periódico na Internet]. 2009 Mai [acesso em 8 Ago 2018]; 26(80): 207-19. Disponível em: http://pepsic.bvsalud.org/scielo.php?script=sci artte $\mathrm{xt} \& \mathrm{pid}=\mathrm{S} 0103-84862009000200006$

13. Corrêa, LM. Déficit específico da linguagem e problemas de linguagem ligados a dificuldades de aprendizagem: um estudo exploratório com vistas à intervenção. In: relatório técnico do Projeto FAPERJ - Cientistas do Nosso Estado 2011. Relações entre DEL (Déficit Específico da Linguagem) e problemas de linguagem no quadro de DAp (Dificuldades de Aprendizagem): módulo sintático, interface gramática-pragmática e caminhos para intervenção, 2011.

14. Shankweiler D, Crain S, Katz L, Fowler AE, Liberman AM, Brady SA et al. Cognitive profiles of reading-disabled children: comparison of language skills in phonology, morphology and syntax. Psychol. sci. [periódico na Internet]. 1995 [acesso em 8 Ago 2018]; 6(3): 81-93. Disponível em: https://pdfs. semanticscholar .org/ab74/3d3b43d26b9d1305535cd1662a 2 29b790abe.pdf

15. Ribeiro VG, Corrêa LMS. O que torna orações relativas e interrogativas de objeto de difícil processamento para crianças? Um estudo experimental com foco no DEL (Déficit Específico de Linguagem) [dissertação]. Rio de Janeiro (RJ): Pontifícia Universidade Católica do Rio de Janeiro; 2012.

16. Capellini SA, Smythe I, Silva C. Protocolo de avaliação de habilidades cognitivo-linguísticas. Livro do profissional e do professor. Marília: Fundepe; 2012.

17. Santos FH, Bueno OFA. Validation of the Brazilian Children's Test of Pseudoword Repetition in Portuguese speakers aged 4 to 10 years. Braz. j. med. biol. res. [periódico na Internet]. 2003 [acesso em 21 Set 2018] 36(11): 1533-47. Disponível em: http://www.scielo.br/scielo.php?script=sci_arttext\&pid=S0100879X20 03001100012 879X2003001100012

18. Salles JF, Piccolo LR, Miná CS. LPI avaliação de leitura de palavras e pseudopalavras isoladas: para crianças do $1^{\circ}$ ao $7^{\circ}$ ano do ensino fundamental. $1^{\text {a }}$ ed. São Paulo: Vetor; 2017.

19. Moojen S, Lamprecht R, Santos RM, Freitas GM, Brodacz $\mathrm{R}$, Siqueira M, et al. Consciência fonológica: instrumento de avaliação sequencial. São Paulo: Casa do Psicólogo; 2003.

20. Corrêa LM. MABILIN Módulos de Avaliação de Habilidades Linguísticas. In: Relatório Técnico Projeto FAPERJ CNE 1999: Procedimentos diferenciados na aquisição do Português e um instrumental psicolinguístico para a avaliação de deficiências de linguagem em crianças, 2000.

21. Cardoso-Martins CC, Pennington BF. Qual é a Contribuição da Nomeação Seriada Rápida para a Habilidade de Leitura e Escrita?: Evidência de Crianças e Adolescentes com e sem Dificuldades de Leitura. Psicol. reflex. crit. [periódico na Internet]. 2001 Jun [acesso em 1 Nov 2018]; 14(2): 387 97. Disponível em: http://www.educadores.diaadia.pr.gov. br/arquivos/File/2010/veiculos_de_comunicacao/PRC/ VOL14N2/7864.PDF
22. Granzotti RBG, Furlan AS, Domenis DR, Fukuda MTH. Memória de trabalho fonológica e consciência fonológica em crianças com dificuldade de aprendizagem. Distúrb. comun. [periódico na Internet]. 2013 Ago [acesso em 4 Nov 2018]; 25(2): 241-52. Disponível em: https://revistas.pucsp.br/index. $\mathrm{php} / \mathrm{dic} /$ article/viewFile /16477/12374

23. Lukasova K, Oliveira DG, Barbosa ACC, Macedo EC. Habilidades de Leitura e Escrita de Crianças Disléxicas e Boas Leitoras. Arq. bras. psicol. (Rio J. 2003). [periódico na Internet]. $2008 \mathrm{Fev}$ [acesso em 1 Nov 2018]; 60(1): 45-54. Disponível em: http://seer.psicologia.ufrj.br/index.php/abp/ article/view/117/144

24. Germano GD, Pinheiro FH, Capellini AS. Desempenho de escolares com dislexia do desenvolvimento em tarefas fonológicas e silábicas. Rev. CEFAC. [periódico na Internet]. 2009 Abr-Jun [acesso em 2 Nov 2018]; 11(2): 213-20. Disponível em: http://www.scielo.br/pdf/rcefac/v11n2/11907.pdf

25. Manis FR, Seidenberg MS, Doi LM. See Dick RAN: Rapid naming and the longitudinal prediction of reading subskills in first and second graders. Scientific Studies of Reading [periódico na Internet]. 1999 Abr [acesso em 2 Nov 2018]; 3(2): 129-57. Disponível em: https://www.researchgate.net/ publication/248943230_See_Dick_RAN_Rapid_Naming and_the_Longitudinal_Prediction_of_Reading_Subskills_in First and Second Graders

26. Gindri G, Keske-Soares M, Mota HB. Memória de trabalho, consciência fonológica e hipótese de escrita. Pró-fono. [periódico na Internet]. 2007 Jul-Set [acesso em 6 Nov 2018]; 19(3): 313-22. Disponível em: http://www.scielo.br/pdf/pfono/ v19n3/a10v19n3.pdf

27. Rodrigues A, Befi-Lopes DM. Memória de curto-prazo fonológica em crianças pré-escolares. CoDas. [periódico na Internet]. 2013 [acesso em 6 Nov 2018]; 25(5): 422-8. Disponível em: http://www.scielo.br/pdf/codas/v25n5/pt_23171782-codas-25-05-00422.pdf

28. Rotta NT. Dificuldades para aprendizagem. In: Rotta, NT, Ohlweiler L, Riesgo RS. Transtornos da aprendizagem: abordagem neurobiológica e multidisciplinar. $2^{\mathrm{a}}$ ed. Porto Alegre: Artmed; 2016. p. 94-104.

29. Fortunato-Tavares T, Rocha CN, Andrade CRF, Befi-Lopes DM, Schochat E, Hestvik A et al. Processamento linguístico e processamento auditivo temporal em crianças com distúrbio específico de linguagem. Pró-fono. [periódico na Internet]. 2009 [acesso em 6 Nov 2018]; 21(4): 279-84. Disponível em: http://www.scielo.br/scielo.php?script=sci arttext\&pid $=$ S0104-56872009000400003

30. Silveira MS. O Déficit Especificamente Linguístico (DEL) e uma avaliação preliminar de sua manifestação em crianças falantes de português [dissertação]. Rio de Janeiro (RJ): Pontifícia Universidade Católica do Rio de Janeiro; 2002. 